\title{
GAMBARAN KEHAMILAN EKTOPIK TERGANGGU DI RSUP PROF. DR. R. D. KANDOU MANADO PERIODE 1 JANUARI 2012 - 31 DESEMBER 2013
}

\author{
${ }^{1}$ Pricilia S. Lomboan \\ ${ }^{2}$ Linda Mamengko \\ ${ }^{2}$ John Wantania
}

\author{
${ }^{1}$ Kandidat Skripsi Fakultas Kedokteran Universitas Sam Ratulangi Manado \\ ${ }^{2}$ Bagian Obstetri Ginekologi Fakultas Kedokteran Universitas Sam Ratulangi Manado \\ Email: Plomboan11_044@yahoo.com
}

\begin{abstract}
In ectopic pregnancy, fertilized ovum is implanted and grows not in a normal place in the endometrium of the uterine cavity. If such pregnancy is threatened to an abortion then it is called threatened ectopic pregnancy. This study aimed to obtain the description of ectopic pregnancy at Prof. Dr. R. D. Kandou Hospital Manado related to age, husband's job, marriage status, parity, pregnancy age, history of abortion, history of fluor albus, implantation site, and hemoglobin level. This was a retrospective descriptive study. The population consisted of all patients treated at Department of Obstetrics Gynecology Prof. Dr. R. D. Kandou Manado Hospital from January 1, 2012 - December 31, 2013. The results showed that of the 49 cases of ectopic pregnancy most of the patients were at the age of 21-35 year (65.30\%); their husbands did not have any jobs (77.55\%); married (73.46\%); parity of 2 (32.65\%); pregnancy age $<8$ weeks (55.10\%); had no history of abortion (65.30\%) or of fluor albus (81.63\%); location in ampullae of uterine tube (97.95\%); Hb level 9-10 g\% and $>10 \mathrm{~g} \%$ (32.65\%).
\end{abstract}

Keywords: ectopic pregnancy, threatened ectopic pregnancy

\begin{abstract}
Abstrak: Kehamilan ektopik adalah kehamilan dengan ovum yang dibuahi berimplantasi dan tumbuh tidak di tempat yang normal yakni endometrium kavum uteri. Bila kehamilan tersebut mengalami proses pengakhiran (abortus) maka disebut kehamilan ektopik terganggu (KET). Penelitian ini bertujuan untuk mengetahui gambaran kehamilan ektopik terganggu di RSUP Prof. Dr. R. D. Kandou Manado dari segi umur, pekerjaan suami, status perkawinan, paritas, usia kehamilan, riwayat abortus, riwayat keputihan, lokasi implantasi, dan kadar Hb. Penelitian ini mnggunakan metode deskriptif retrospektif. Populasi ialah seluruh pasien yang dirawat di Bagian Obstetri Ginekologi RSUP Prof. Dr. R. D. Kandou Manado periode 1 Januari 2012 - 31 Desember 2013. Hasil penelitian memperlihatkan dari 49 kasus KET, pasien terbanyak berumur 21-35 tahun (65,30\%); suami yang tidak bekerja (77,55\%), status menikah (73,46\%), paritas 2 (32,65\%), usia kehamilan <8 minggu (55,10\%), tanpa riwayat abortus (65,30\%), tanpa riwayat keputihan (81,63\%), lokasi pada ampula tuba (97,95\%), serta kadar $\mathrm{Hb}$ 9-10 g\% dan $\mathrm{Hb}>10$ g\% (32,65\%).
\end{abstract}

Kata kunci: kehamilan ektopik, KET

Kehamilan ektopik adalah kehamilan dimana sel telur yang dibuahi berimplantasi dan tumbuh di luar endometrium kavum uterus. ${ }^{1} \quad$ Kehamilan ektopik terganggu (KET) dapat menyebabkan terjadi abortus maupun ruptur yang menyebabkan penurunan keadaan umum pasien. ${ }^{2}$

Sebagian besar wanita yang mengalami kehamilan ektopik berumur antara 20-40 tahun dengan umur rata-rata 
30 tahun. Lebih dari 60\% kehamilan ektopik terjadi pada wanita 20-30 tahun dengan sosio-ekonomi rendah dan tinggal didaerah dengan prevalensi gonore dan prevalensi tuberkulosa yang tinggi. ${ }^{3}$

Penelitian Cunningham di Amerika Serikat melaporkan bahwa kehamilan ektopik terganggu (KET) lebih sering dijumpai pada wanita kulit hitam dari pada kulit putih karena prevalensi penyakit peradangan pelvis lebih banyak pada wanita kulit hitam. Frekuensi kehamilan ektopik terganggu yang berulang $1-14,6 \%{ }^{4}$

Trias gejala dan tanda dari kehamilan ektopik adalah riwayat keterlambatan haid atau amenorrhea yang diikuti perdarahan abnormal (60-80\%), nyeri abdominal atau pelvik (95\%). Biasanya kehamilan ektopik baru dapat ditegakkan pada usia kehamilan 6-8 minggu saat timbulnya gejala tersebut di atas. Gejala lain yang muncul biasanya sama seperti gejala pada kehamilan muda, seperti mual, rasa penuh pada payudara, lemah, nyeri bahu, dan dispareunia. Selain itu pada pemeriksaan fisik didapatkan pelvic tenderness, pembesaran uterus dan massa adneksa.,

Faktor risiko yang diperkirakan sebagai penyebabnya ialah: Infeksi saluran telur (salpingitis) dapat menimbulkan gangguan pada motilitas saluran telur; riwayat operasi tuba; cacat bawaan pada tuba seperti tuba sangat panjang; kehamilan ektopik sebelumnya; aborsi tuba; pemakaian IUD; kelainan zigot, yaitu kelainan kromosom; bekas radang pada tuba menyebabkan perubahan - perubahan pada endosalping sehingga walaupun fertilitas dapat terjadi, gerakan ovum ke uterus terlambat; operasi plastik pada tuba; dan abortus buatan. ${ }^{7,8}$

Penanganan kehamilan ektopik pada umunya ialah laparotomi. Dalam tindakan demikian, beberapa hal harus diperhatikan dan dipertimbangkan yaitu: kondisi penderita, keinginan penderita akan fungsi reproduksinya, lokasi kehamilan ektopik, kondisi anatomik organ pelvis, kemampuan teknik bedah mikro dari dokter operator, dan kemampuan teknologi fertilisasi invitro setempat. Hasil perimbangan ini menentukan apakah perlu dilakukan salpingektomi pada kehamilan tuba, atau dapat dilakukan ppembedahan konservatif dalam arti hanya dilakukan salpingostomi atau reanastomosis tuba. ${ }^{9}$

Kehamilan ektopik dapat mengancam nyawa; oleh karena itu deteksi dini dan pengakhiran kehamilan merupakan tatalaksana yang disarankan yaitu dengan obat-obatan atau operasi. ${ }^{10}$

\section{METODE PENELITIAN}

Penelitian ini merupakan penelitian deskriptif retrospektif. Tempat penelitian ialah bagian Rekam Medik RSUP Prof. Dr. R. D. Kandou Manado. Populasi ialah semua pasien kasus ginekologi yang dirawat inap di Bagian Obstetri dan Ginekologi RSUP Prof. Dr. R. D. Kandou Manado periode 1 Januari 2012 - 31 Desember 2013. Sampel ialah semua penderita yang didiagnosis kehamilan ektopik terganggu (KET) di Bagian Obstetri dan Ginekologi RSUP Prof. Dr. R. D. Kandou Manado periode 1 Januari 2012 - 31 Desember 2013.

Pengolahan data dilakukan secara manual dan menggunakan komputer. Data disusun dalam bentuk distribusi frekuensi.

\section{HASIL PENELITIAN}

Berdasarkan hasil penelitian di Bagian rekam medik RSUP Prof. Dr. R. D. Kandou tentang kasus kehamilan ektopik terganggu periode Januari 2012-Desember 2013 diperoleh data yang disajikan dalam bentuk tabel distribusi.

Tabel 1. Distribusi kehamilan ektopik menurut kelompok umur

\begin{tabular}{ccccc}
\hline \multirow{2}{*}{ Umur } & $\mathbf{N}$ & $\mathbf{2 0 1 2}$ & \multicolumn{2}{c}{$\mathbf{2 0 1 3}$} \\
& & $\mathbf{N}$ & $\mathbf{\%}$ \\
\hline$\leq 20$ & 2 & 12,5 & 2 & 6,06 \\
$21-35$ & 8 & 50 & 24 & 72,72 \\
$36-45$ & 6 & 37,5 & 7 & 21,21 \\
$\geq 46$ & 0 & 0 & 0 & 0 \\
\hline Total & $\mathbf{1 6}$ & $\mathbf{1 0 0}$ & $\mathbf{3 3}$ & $\mathbf{1 0 0}$ \\
\hline
\end{tabular}


Tabel 2. Distribusi kehamilan ektopik menurut pekerjaan suami

\begin{tabular}{ccccc}
\hline & \multicolumn{2}{c}{$\mathbf{2 0 1 2}$} & \multicolumn{2}{c}{$\mathbf{2 0 1 3}$} \\
Pekerjaan & $\mathbf{N}$ & $\mathbf{\%}$ & $\mathbf{N}$ & $\mathbf{\%}$ \\
\hline Tidak Bekerja & 11 & 68,75 & 27 & 81,81 \\
Pegawai Swasta & 1 & 6,25 & 2 & 6,06 \\
Pelajar/Mahsiswa & 1 & 6,25 & 2 & 6,06 \\
Buruh Tani & 1 & 6,25 & 1 & 3,03 \\
Pegawai Negeri & 2 & 12,5 & 1 & 3,03 \\
Sopir & 0 & 0 & 0 & 0 \\
\hline Total & $\mathbf{1 6}$ & $\mathbf{1 0 0}$ & $\mathbf{3 3}$ & $\mathbf{1 0 0}$ \\
\hline
\end{tabular}

Tabel 3. Distribusi kehamilan ektopik menurut status pernikahan

\begin{tabular}{ccccc}
\hline & \multicolumn{2}{c}{$\mathbf{2 0 1 2}$} & \multicolumn{2}{c}{$\mathbf{2 0 1 3}$} \\
Status & $\mathbf{N}$ & $\mathbf{\%}$ & $\mathbf{N}$ & $\mathbf{\%}$ \\
\hline Menikah & 15 & 93,75 & 21 & 63,63 \\
Tidak & 1 & 6,25 & 12 & 36,36 \\
menikah & & & & \\
\hline Total & $\mathbf{1 6}$ & $\mathbf{1 0 0}$ & $\mathbf{3 3}$ & $\mathbf{1 0 0}$ \\
\hline
\end{tabular}

Tabel 4. Distribusi kehamilan ektopik menurut paritas

\begin{tabular}{ccccc}
\hline & \multicolumn{2}{c}{$\mathbf{2 0 1 2}$} & \multicolumn{2}{c}{$\mathbf{2 0 1 3}$} \\
Paritas & $\mathbf{N}$ & $\mathbf{\%}$ & $\mathbf{N}$ & $\mathbf{\%}$ \\
\hline 0 & 3 & 18,75 & 12 & 36,36 \\
1 & 6 & 37,5 & 9 & 27,27 \\
2 & 5 & 31,25 & 11 & 33,33 \\
3 & 2 & 12,5 & 1 & 3,03 \\
$\geq 4$ & 0 & 0 & 0 & 0 \\
\hline Total & $\mathbf{1 6}$ & $\mathbf{1 0 0}$ & $\mathbf{3 3}$ & $\mathbf{1 0 0}$ \\
\hline
\end{tabular}

Tabel 5. Distribusi kehamilan ektopik menurut usia kehamilan

\begin{tabular}{ccccc}
\hline Umur & \multicolumn{2}{c}{$\mathbf{2 0 1 2}$} & $\mathbf{2 0 1 3}$ & \\
(minggu) & $\mathbf{N}$ & $\mathbf{\%}$ & $\mathbf{N}$ & $\mathbf{\%}$ \\
\hline$<8$ & 7 & 43,75 & 20 & 60,60 \\
$8-12$ & 7 & 43,75 & 11 & 33,33 \\
$>12$ & 2 & 12,5 & 2 & 6,06 \\
\hline Total & $\mathbf{1 6}$ & $\mathbf{1 0 0}$ & $\mathbf{3 3}$ & $\mathbf{1 0 0}$ \\
\hline
\end{tabular}

Tabel 6. Distribusi kehamilan ektopik menurut riwayat abortus

\begin{tabular}{ccccc}
\hline Riwayat & \multicolumn{2}{c}{$\mathbf{2 0 1 2}$} & \multicolumn{2}{c}{$\mathbf{2 0 1 3}$} \\
Abortus & $\mathbf{N}$ & $\mathbf{\%}$ & $\mathbf{N}$ & $\mathbf{\%}$ \\
\hline Tidak ada & 13 & 81,25 & 19 & 57,57 \\
1 kali & 3 & 18,75 & 12 & 36,36 \\
2 kali & 0 & 0 & 1 & 3,03 \\
$\geq 3$ & 0 & 0 & 1 & 3,03 \\
\hline Total & $\mathbf{1 6}$ & $\mathbf{1 0 0}$ & $\mathbf{3 3}$ & $\mathbf{1 0 0}$ \\
\hline
\end{tabular}

Tabel 7. Distribusi kehamilan ektopik menurut riwayat keputihan

\begin{tabular}{ccccc}
\hline Riwayat & \multicolumn{2}{c}{$\mathbf{2 0 1 2}$} & \multicolumn{2}{c}{$\mathbf{2 0 1 3}$} \\
Keputihan & $\mathbf{N}$ & $\mathbf{\%}$ & $\mathbf{N}$ & $\mathbf{\%}$ \\
\hline Ya & 5 & 31,25 & 4 & 12,12 \\
Tidak & 11 & 68,75 & 29 & 87,87 \\
\hline Total & $\mathbf{1 6}$ & $\mathbf{1 0 0}$ & $\mathbf{3 3}$ & $\mathbf{1 0 0}$ \\
\hline
\end{tabular}

Tabel 8. Distribusi kehamilan ektopik menurut lokasi implantasi

\begin{tabular}{ccccc}
\hline Lokasi Implantasi & \multicolumn{2}{c}{$\mathbf{2 0 1 2}$} & \multicolumn{2}{c}{$\mathbf{2 0 1 3}$} \\
$\mathbf{N}$ & $\mathbf{\%}$ & $\mathbf{N}$ & $\mathbf{\%}$ \\
\hline Ampula Tuba & 15 & 93,75 & 33 & 100 \\
Intersisial Tuba & 0 & 0 & 0 & 0 \\
Infundibulum Tuba & 0 & 0 & 0 & 0 \\
Ismus Tuba & 0 & 0 & 0 & 0 \\
Kornu uterus & 0 & 0 & 0 & 0 \\
abdominal & 0 & 0 & 0 & 0 \\
Ovarium & 1 & 6,25 & 0 & 0 \\
Cervical & 0 & 0 & 0 & 0 \\
\hline Total & $\mathbf{1 6}$ & $\mathbf{1 0 0}$ & $\mathbf{3 3}$ & $\mathbf{1 0 0}$ \\
\hline
\end{tabular}

Tabel 9. Distribusi kehamilan ektopik menurut kadar $\mathrm{Hb}$

\begin{tabular}{crrcc}
\hline $\mathbf{H b}$ & \multicolumn{2}{c}{$\mathbf{2 0 1 2}$} & \multicolumn{2}{c}{$\mathbf{2 0 1 3}$} \\
$\mathbf{( g r \% )}$ & $\mathbf{N}$ & $\mathbf{\%}$ & \multicolumn{1}{c}{$\mathbf{N}$} & $\mathbf{\%}$ \\
\hline$<6$ & 0 & 0 & 2 & 6,06 \\
$6-8$ & 4 & 25 & 11 & 33,33 \\
$9-10$ & 9 & 56,25 & 7 & 21,21 \\
$>10$ & 3 & 18,75 & 13 & 39,39 \\
\hline Total & $\mathbf{1 6}$ & $\mathbf{1 0 0}$ & $\mathbf{3 3}$ & $\mathbf{1 0 0}$ \\
\hline
\end{tabular}




\section{BAHASAN}

Dari hasil pengumpulan data yang dilakukan dibagian rekam medis di BLU RSUP Prof. Dr. R. D. Kandou Manado pada periode 1 Januari 2012-31 Desember 2013, ditemukan total sebanyak 152 kasus yang terdiagnosis kehamilan ektopik, dengan rincian: pada periode 1 Januari 2012-31 Desember 2012 sebanyak 68 kasus dan pada periode 1 Januari 2013-31 Desember 2013 sebanyak 84 kasus. Namun, dari 152 kasus tersebut, sampel yang diambil hanya 49 kasus saja karena data yang tersedia di rekam medis hanya sebanyak 49 kasus.

Pada Tabel 1 didapatkan bahwa kasus KET di RSUP Prof. Dr. R. D. Kandou Manado pada periode 1 Januari 2012-31 Desember 2013, paling banyak ditemukan pada golongan umur 21-35 tahun yaitu sebanyak 32 kasus (65,30\%) dan tidak didapatkan kasus pada kelompok umur $\geq 46$ tahun. Umur 20-39 tahun merupakan usia produktif seorang wanita untuk hamil sehingga KET lebih tinggi. Pada umur $<20$ tahun organ reproduksi wanita belum matang sepenuhnya dan pada usia $\geq 40$ tahun seorang wanita tidak produktif lagi. Sebagian besar wanita mengalami kehamilan ektopik berumur antara 20-40 tahun dengan rata-rata umur 30 tahun. $^{1}$

Pada Tabel 2 didapatkan bahwa kasus KET di RSUP Prof. Dr. R. D. Kandou Manado, paling banyak ditemukan suami yang tidak bekerja yaitu sebanyak 38 kasus (77,55 \%) dan tidak didapatkan kasus dengan pekerjaan suami sopir. Kehamilan ektopik lebih sering terjadi pada keadaan sosio ekonomi rendah. ${ }^{11}$

Pada Tabel 3 didapatkan kasus KET di RSUP Prof. Dr. R. D. Kandou Manado paling banyak ditemukan status menikah yaitu sebanyak 36 kasus (73,46\%) sednagkan status tidak menikah sebanyak 13 kasus (26,53 \%).

Pada Tabel 4 didapatkan bahwa kasus KET di RSUP Prof. Dr. R. D. Kandou Manado paling banyak terdapat pada kelompok dengan paritas 2, yaitu sebanyak 16 kasus (32,65\%) dan tidak didapatkan kasus dengan kelompok paritas $\geq 4$. Paritas
2-3 merupakan paritas yang paling aman, ditinjau dari sudut kematian maternal sedangkan paritas 1 dan paritas tinggi mempunyai angka kematian maternal lebih tinggi. Makin tinggi paritas, makin tinggi kematian maternal. Risiko pada paritas 1 dapat ditangani dengan asuhan obstetrik yang lebih baik, sedangkan kehamilan pada paritas tinggi dapat dikurangi atau dicegah dengan KB. Sebagian kehamilan pada paritas tinggi tidak direncanakan. ${ }^{12}$

Pada Tabel 5 didapatkan bahwa kasus KET di RSUP Prof. Dr. R. D. Kandou Manado paling banyak terdapat pada kelompok usia kehamilan $<8$ minggu, yaitu sebanyak 27 kasus (55,10\%) sedangkan yang paling sedikit pada kelompok usia kehamilan $>12$ minggu sebanyak 4 kasus $(8,16 \%)$.

Pada Tabel 6 didapatkan bahwa kasus KET di RSUP Prof. Dr. R. D. Kandou Manado paling banyak terdapat pada kelompok tanpa riwayat abortus, yaitu sebanyak 32 kasus (65,30\%) sedangkan angka kejadian KET dengan riwayat abortus 1 kali sebanyak 15 kasus (30,61\%), riwayat abortus 2 kali sebanyak 1 kasus (2,04\%), dan riwayat abortus $\geq 3$ kali sebanyak 1 kasus ( 2,04\%).

Pada Tabel 7 didapatkan bahwa kasus KET di RSUP Prof. Dr. R. D. Kandou Manado paling banyak terdapat pada kelompok tanpa riwayat keputihan, yaitu sebanyak 40 kasus (81,63\%) sedangkan yang dengan riwayat keputihan sebanyak 9 kasus $(18,36 \%)$.

Pada Tabel 8 didapatkan bahwa kasus KET di RSUP Prof. Dr. R. D. Kandou Manado paling banyak terdapat pada ampula tuba yaitu, sebanyak 48 kasus (97,95 \%) dan pada ovarium sebanyak 1 kasus (2,04 \%).

Pada Tabel 9 didapatkan bahwa kasus kehamilan ektopik terganggu di RSUP Prof. Dr. R. D. Kandou Manado, paling banyak terdapat pada kelompok $\mathrm{Hb} 9-10$ g\% yaitu sebanyak 16 kasus (32,65\%), dan $\mathrm{Hb}>10 \mathrm{~g} \%$ sebanyak 16 kasus (32,65\%). Angka kejadian kehamilan ektopik paling sedikit kelompok $\mathrm{Hb}<6$ g\% sebanyak 2 kasus (4,08\%). Hal ini menunjukkan bahwa 
sebagian besar ibu penderita KET yang datang ke rumah sakit belum dalam keadaan anemia berat melainkan anemia sedang atau dalam batas normal. Hal ini mungkin disebabkan penanganan penderita KET sangat cepat dan tepat. Anemia berat yang dialami ibu penderita KET disebabkan oleh perdarahan vaginal yang telah lama dialami.

\section{SIMPULAN}

Dari hasil penelitian yang dilakukan dibagian rekam medik RSUP Prof. Dr. R. D. Kandou Manado dapat disimpul-kan bahwa kasus kehamilan ektopik terganggu paling banyak ditemukan pada kelompok umur 21-35 tahun, dengan suami yang tidak mempunyai pekerjaan, status menikah, jumlah paritas 2, usia kehamilan $<8$ minggu, tidak ada riwayat abortus, tidak ada riwayat keputihan, lokasi pada ampula tuba, dengan kadar $\mathrm{Hb}$ 9-10 g\% dan $\mathrm{Hb}$ $>10 \mathrm{~g} \%$.

\section{SARAN}

1. Mengingat kasus kehamilan ektopik merupakan kasus darurat dan dapat mengancam nyawa maka pada wanita hamil usia rentan kehamilan ektopik disarankan untuk melakukan deteksi dini.

2. Memberikan penjelasan pada setiap ibu hamil dan suaminya tentang gejalagejala yang timbul akibat kehamilan tidak normal.

3. Pelayanan yang lebih menyeluruh untuk menurunkan angka kejadian kehamilan ektopik terganggu. Perlu adanya sentralisasi data, agar pengambilan data dapat terfokus, sehingga proses pengambilan data lebih akurat.

\section{DAFTAR PUSTAKA}

1. Wiknjosastro H. Ilmu Kebidanan (Edisi Ketiga). Jakarta: Yayasan Bina Pustaka Sarwono Prawiroharjo, 1999.

2. Wiknjosastro H. Ilmu Bedah Kebidanan. Jakarta: Yayasan Bina Pustaka Sarwono Prawiroharjo, 2000.

3. Wibowo B. Kehamilan Ektopik. In: Ilmu Kebidanan (Edisi III). Jakarta: Yayasan Bina Pustaka Sarwono Prawiroharjo, 2007.

4. Cunningham FG, Gant NF, Leveno KJ. Ectopic Pregnancy. In: William's Obstetrics (22nd ed.). USA: The Mc Graw - Hill Company, 2005.

5. Mochtar, Rustam. Sinopsis Obstetri Jilid 1. Jakarta: EGC, 2000; p. 226-35.

6. Saifiddin AB. Kehamilan Ektopik Terganngu. In: Affandi B, Waspodo B, editors. Buku Panduan Praktis Pelayanan Kesehatan Maternal dan Neonatal (Edisi I). Jakarta: Yayasan Bina Pustaka Sarwono Prawirohardjo, 2002.

7. Rachimhadhi T. Kehamilan Ektopik. In: Ilmu Bedah Kebidanan (Edisi I). Jakarta: Yayasan Bina Pustaka Sarwono Prawiroharjo, 2005; p. 198210.

8. Sukarni I, ZH Margareth. Kehamilan Persalinan dan Nifas, Jogjakarta: Nuha Medika, 2013.

9. Prawirohardjo S. Ilmu Kebidanan (Edisi Keempat). Jakarta: Bina Pustaka Sarwono Prawirohardjo, 2012.

10. Yulaikh L. Seri Asuhan Kebidanan. Jakarta: EGC, 2009.

11. Pisarska. Insidence and risk factors for ectopic pregnancy. Clinical Obstetrics and Gynecology-Abstract. 1999;(1).

12. Manuaba IBG. Ilmu Kebidanan Penyakit Kandungan dan Keluarga Berencana untuk Pendidikan Bidan. Jakarta: EGC, 2002. 